rhage (performed in most patients by one specialist surgeon). Indeed, comparison with the report of Ratnoff and Patek ${ }^{9}$ showed that in patients with ascites there has been virtually no change in mortality in the last 50 years.

There are several explanations for the poor life expectancy of patients with cirrhosis. The proportion for whom there was any form of "specific" treatment, such as corticosteroids, penicillamine, or venesection, barely exceeded $5 \%$. Most patients already had decompensated liver disease when first seen and died of progressive liver failure or hepatoma, a tumour which has proved particularly resistant to treatment. Fewer succumbed to gastrointestinal haemorrhage, nearly always as a result of hepatorenal failure rather than exsanguination. Lastly, the proportion of patients with alcoholic cirrhosis who abstained after discharge averaged only $19 \%$ over the 18 years.

Because alcoholic cirrhosis is emerging as the most common form of the disease, ways must be found to detect alcoholics at risk of developing liver damage and treatment programmes devised which will lead to successful abstinence. The causes of cryptogenic cirrhosis, which still accounts for a significant proportion of patients, also need to be identified. Diagnosis must be made before decompensation has occurred, otherwise we shall continue to waste resources in unsuccessful treatment of patients with irreversible liver disease.

We are grateful to our medical colleagues and records staff for invaluable help in identifying patients; Mr P G Bevan for expert surgical care; Dr R M Whittington, HM Coroner for Birmingham, for permission to inspect records; and Inspector C J Clarke for help in obtaining files.

JBS was in receipt of a Sheldon clinical research fellowship from the West Midlands Regional Health Authority.

Part of this investigation was reported at a meeting of the Association of Physicians of Great Britain and Ireland in April 1980.

\section{References}

${ }^{1}$ General Register Office. Registrar General's statistical review of England and Wales, 1950-1973. London: HMSO, 1975.

2 Office of Population Censuses and Surveys. Mortality statistics. Review of the Registrar General on deaths in England and Wales, 1974 et seq. London: HMSO, 1979.

${ }^{3}$ Stone WD, Islam NRK, Paton A. The natural history of cirrhosis. Experience with an unselected group of patients. $Q \mathcal{F}$ Med $1968 ; 37$ : 119-32.

4 Jain S, Paton A, Wansbrough-Jones MH. Cirrhosis in Birmingham. Midland Medical Review 1973;9:13-6.

${ }_{5}$ Nie NH, Hull CH, Jenkins JG, Steinbrenner K, Bent DH. Statistical package for the social sciences. New York: McGraw-Hill, 1975.

- Peto R, Pike MC, Armitage P, et al. Design and analysis of randomized clinical trials requiring prolonged observation of each patient. II Analysis and examples. Br F Cancer 1977;35:1-39.

${ }^{7}$ Spring JA, Buss DH. Three centuries of alcohol in the British diet. Nature 1977 ;270:567-72.

${ }^{8}$ Pequignot G. Augmentation du risque de cirrhose en fonction de la ration d'alcool. Revue de l'alcoolisme 1974;20:191-202.

- Ratnoff OD, Patek AJ Jr. The natural history of Laennec's cirrhosis of the liver; an analysis of 386 cases. Medicine (Baltimore) 1942;21:207-68.

(Accepted 21 November 1980)

\title{
How dangerous are falls in old people at home?
}

\author{
DEIDRE WILD, U S L NAYAK, B ISAACS
}

\begin{abstract}
From a survey in six general practices information was obtained on 125 people aged 65 and over who fell in their own homes. Three fractured their femurs and 15 had other fractures; most of the rest suffered only trivial injuries. Twenty lay on the floor for more than one hour; none were known to have suffered hypothermia. One-quarter of these patients died within one year of the fall, five times as many as in an age- and sex-matched control group; while of those who lay on the floor for more than one hour, half died within six months of the fall. Factors associated with mortality from falls were impaired mobility, abnormal balance, and a disturbed pattern of gait.

Falls at home in old age are often indicative of the presence of severe ill health.
\end{abstract}

\section{Introduction}

Much attention has been paid to fractures of the femur in old age resulting from falls ${ }^{12}$; but most old people who fall

\footnotetext{
University Department of Geriatric Medicine, Selly Oak Hospital, Birmingham B29 6JD

DEIDRE WILD, RGN, BA, research associate

U S L NAYAK, MSC, PHD, lecturer in bioengineering

B ISAACS, MD, FRCP, professor
}

over at home do not break any bones. ${ }^{3}$ Some studies have been made, ${ }^{5}$ but little is known about the causes of these falls, what can be done to prevent them, what resources are devoted to those who fall, and what happens to them.

In an attempt to find answers to these questions we organised a survey of falls at home in people aged 65 and over in the Birmingham area. A group of persons reporting falls were matched for age and sex with a control group, and both were followed for one year after the fall.

\section{Material and methods}

Six general practices in and near Birmingham kindly agreed to take part and to notify a research nurse of all falls occurring in people aged 65 and over that came to their attention during an observation period of one year. Falls were defined as "untoward events which resulted in the subject involuntarily coming to rest on the ground." This excluded episodes of staggering against the wall or falling into a chair or on to a bed. In a few instances consciousness was lost and there was a suspicion of an epileptic fit; and in two cases the fall represented the onset of a stroke. The location included the house and its immediate surroundings, the front and back steps, the courtyard, and the garden but excluded falls in the street. Most of the participating doctors looked after some patients in local authority residential homes, and any of those who fell were included in the survey.

Information about falls was sought from the general practitioners themselves, their receptionists, community nurses, home helps, staff of residential homes, police, and other informants. Most falls were reported by the practitioner himself and were accompanied by at least a minor injury. Falls were reported at a rate of 20 falls per 
BRITISH MEDICAL JOURNAL VOLUME $282 \quad 24$ JANUARY 1981

1000 population aged 65 and over per year. The follow-up studies suggested that this was only a fraction of all falls occurring in the age group, most of which did not come to the notice of the doctor.

The control group was obtained by drawing at random from the list of the general practitioner the name of a patient of the same sex and the same year of birth as the faller. All but one faller and all controls agreed to take part fully in the study; but sufficient information was obtained about the circumstances of the fall in the one who refused to allow her inclusion in the study.

Table I shows the age and sex distributions of fallers and controls. Most fallers were aged 75 and over. There were five times as many women as men, whereas in the population from which they were drawn there were twice as many women as men.

TABLE I-Age and sex distributions of fallers and controls

\begin{tabular}{lrcc}
\hline $\begin{array}{c}\text { Age group } \\
\text { (years) }\end{array}$ & Men & Women & Total \\
\hline $65-74$ & 7 & 15 & 22 \\
$75-84$ & 10 & 60 & 70 \\
85 and over & 3 & 30 & 33 \\
\hline Total & 20 & 105 & 125 \\
\hline
\end{tabular}

A research nurse visited the place where the fall had occurred within seven days of its occurrence, interviewed the faller and any relative or other informants, and made a check of gait, balance, blood pressure in the sitting and standing positions, and drug consumption. The corresponding control was visited usually in the same week, and similar information was obtained. Fallers and controls were revisited three and 12 months after the original incident, when information was obtained about further falls, any change in mobility or living conditions, and the use made of hospital and residential care services.

\section{Results}

The retrospective information obtained from controls at the threemonth follow-up was used as a basis for estimating the incidence of falls in a sample of the elderly population (table II), which proved to be almost 20 times higher than the incidence of reported falls. Injury, however, was rare in these cases; almost certainly the original sample of fallers was biased by including mostly people who were injured when they fell.

TABLE II-Incidence of falls in controls recalled at three-month follow-up

\begin{tabular}{|c|c|c|c|}
\hline$\underset{\text { (years) }}{\text { Age }}$ & $\begin{array}{c}\text { No } \\
\text { at risk }\end{array}$ & $\begin{array}{c}\text { No of falls } \\
\text { recalled at } \\
\text { three months }\end{array}$ & $\begin{array}{l}\text { Estimated annual incidence of } \\
\text { falls/1000 of age-sex } \\
\text { group based on recall }\end{array}$ \\
\hline $\begin{array}{l}65-74 \\
75-84 \\
85 \text { and over }\end{array}$ & $\begin{array}{r}7 \\
10 \\
3\end{array}$ & $\begin{array}{l}0^{\text {Men }} \\
1 \\
0\end{array}$ & $\overline{400}$ \\
\hline $\begin{array}{l}65-74 \\
75-84 \\
85 \text { and over }\end{array}$ & $\begin{array}{l}15 \\
60 \\
30\end{array}$ & $\begin{array}{l}\text { Women } \\
1 \\
9 \\
5\end{array}$ & $\begin{array}{l}267 \\
600 \\
667\end{array}$ \\
\hline Total & 125 & 16 & - \\
\hline
\end{tabular}

Thirty falls occurred on change of position-for example, on rising from bed, chair, toilet; 36 occurred unexpectedly during walking with no accompanying symptoms and no external hazard; and 35 occurred during some potentially hazardous activity such as climbing stairs or walking on an irregular surface; but in only nine of these was there clear evidence that the fall had actually resulted from tripping or slipping. The expression often used by patients, "I must have slipped," was not taken as necessarily the same as "I slipped."

Most premonitory symptoms were rare, and many patients who used such expressions as "dizzy" or "lightheaded" were inconsistent about this.

Most falls occurred in the bedroom or living room; there were
14 in the kitchen and 11 in the bathroom. Most falls occurred by day with only 21 occurring between midnight and 8 am.

Most subjects rose or were helped to their feet rapidly; but 20 remained on the floor unable to rise for more than one hour, four of these for more than six hours. None of these had a fracture and none was known to have suffered hypothermia, though temperature recordings were not obtained.

Comparison between fallers and controls-Table III shows selected comparisons between fallers and controls. Fallers were very much

\begin{tabular}{|c|c|c|c|c|c|}
\hline & & & & $\begin{array}{l}\text { No of } \\
\text { fallers }\end{array}$ & $\begin{array}{c}\text { No of } \\
\text { controls }\end{array}$ \\
\hline $\begin{array}{l}\text { Previous falls: } \\
\text { None } \\
\text { One . } \\
\text { More than one }\end{array}$ & $\begin{array}{l}\cdots \\
\cdots\end{array}$ & $\begin{array}{l}. \\
\cdots\end{array}$ & $\begin{array}{l}\cdots \\
\cdots\end{array}$ & $\begin{array}{l}43 \\
18 \\
63^{*}\end{array}$ & $\begin{array}{r}101 \\
12 \\
12\end{array}$ \\
\hline $\begin{array}{l}\text { Mobility: } \\
\text { Outdoors unsuppo } \\
\text { Indoors unsuppor } \\
\text { Indoors unsteady }\end{array}$ & $\begin{array}{l}\text { orted } \\
\text { rted } \\
\text { or imm }\end{array}$ & $\ddot{x}$ & $\begin{array}{l}. \\
\cdots\end{array}$ & $\begin{array}{l}46 \\
50 \\
29\end{array}$ & $\begin{array}{r}87 \\
30 \\
8\end{array}$ \\
\hline $\begin{array}{l}\text { Gait: } \\
\text { Normal, safe } \\
\text { Safe with aid } \\
\text { Abnormal, unsafe } \\
\text { Unable to walk }\end{array}$ & $\begin{array}{l}\cdots \\
\cdots\end{array}$ & $\begin{array}{l}\ddot{ } \\
\therefore \\
\cdots\end{array}$ & $\begin{array}{l}\cdots \\
\cdots \\
\cdots\end{array}$ & $\begin{array}{l}40 \\
5 \\
67 \\
10 \dagger\end{array}$ & $\begin{array}{r}86 \\
1 \\
33 \\
5\end{array}$ \\
\hline $\begin{array}{l}\text { Balance: } \\
\text { Normal } \\
\text { Abnormal } \\
\text { Not tested }\end{array}$ & $\begin{array}{l}\cdots \\
\cdots\end{array}$ & $\begin{array}{l}\cdots \\
\cdots\end{array}$ & $\begin{array}{l}\cdots \\
\cdots\end{array}$ & $\begin{array}{l}38 \\
75 \\
12\end{array}$ & $\begin{array}{r}90 \\
31 \\
4\end{array}$ \\
\hline $\begin{array}{ll}\text { Set test: } & \\
\text { Good } & \ldots \\
\text { Moderate } & \ldots \\
\text { Poor.. } & \cdots\end{array}$ & $\begin{array}{l}\cdots \\
\cdots\end{array}$ & $\begin{array}{l}\ddot{ } \\
\cdots\end{array}$ & $\begin{array}{l}\cdots \\
\cdots\end{array}$ & $\begin{array}{l}48 \\
60 \\
17\end{array}$ & $\begin{array}{r}85 \\
40 \\
0\end{array}$ \\
\hline $\begin{array}{l}\text { Continence: } \\
\text { Continent .. } \\
\text { Incontinent.. }\end{array}$ &.. & $\therefore$ & $\because$ & $\begin{array}{l}92 \\
33\end{array}$ & $\begin{array}{c}110 \\
12 \ddagger\end{array}$ \\
\hline
\end{tabular}

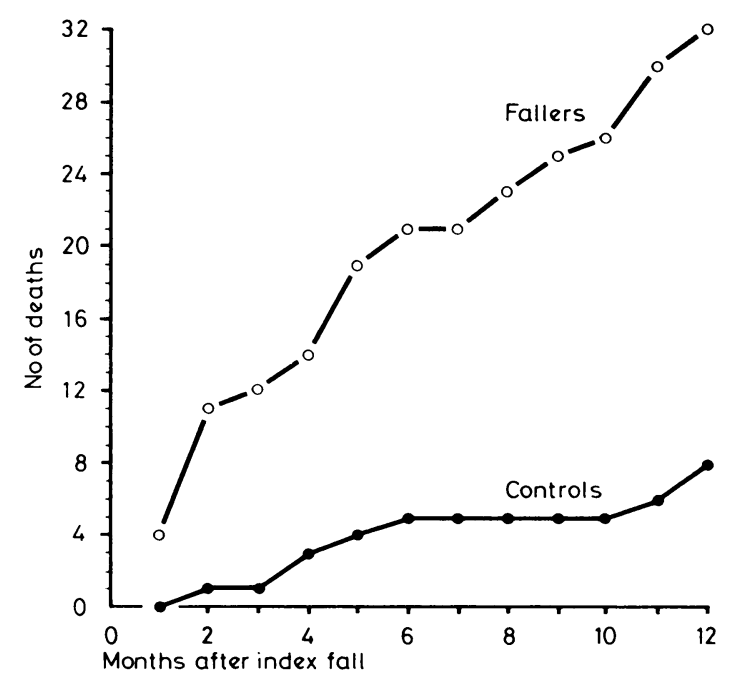

Cumulative mortality in 125 fallers and 125 controls in 12 months after index fall.

more likely than controls to have had previous falls and limited mobility. The gait of fallers was more likely to be visibly abnormal, as was their response to tests of balance; but these results may have been affected by the fact that these tests were carried out after the fall had occurred. More fallers than controls performed poorly on a test of mental function, and more fallers than controls were incontinent, although only a minority had either symptom.

Postural hypotension-Four fallers and eight controls showed a drop of between 20 and $40 \mathrm{~mm} \mathrm{Hg}$ in systolic pressure after standing up from the sitting position. Eleven fallers and six controls showed a drop of more than $40 \mathrm{~mm} \mathrm{Hg}$. Of the 11 fallers with a blood pressure drop of more than $40 \mathrm{~mm} \mathrm{Hg}$, three had fallen on change of posture and nine were receiving antihypertensive drugs or drugs with a hypotensive action. 
Drugs-Fallers were more likely than controls to have taken drugs within 24 hours of the fall (or of the corresponding time in the controls), especially hypnotics, tranquillisers, and sedatives. In general, fallers were more ill and disabled than were their age- and sex-matched controls.

Mortality-The mortality of fallers and controls is shown diagrammatically in the figure. At the end of one year 32 fallers, a quarter of the series, had died compared with eight controls. The cause of death was obtained from the death certificates, and there was no difference in the diagnostic categories used between the fallers and the controls. No faller was recorded as having died as a result of a fracture or hypothermia. Table IV records factors associated with excess mortality.

TABLE IV-Factors associated with excess mortality in fallers

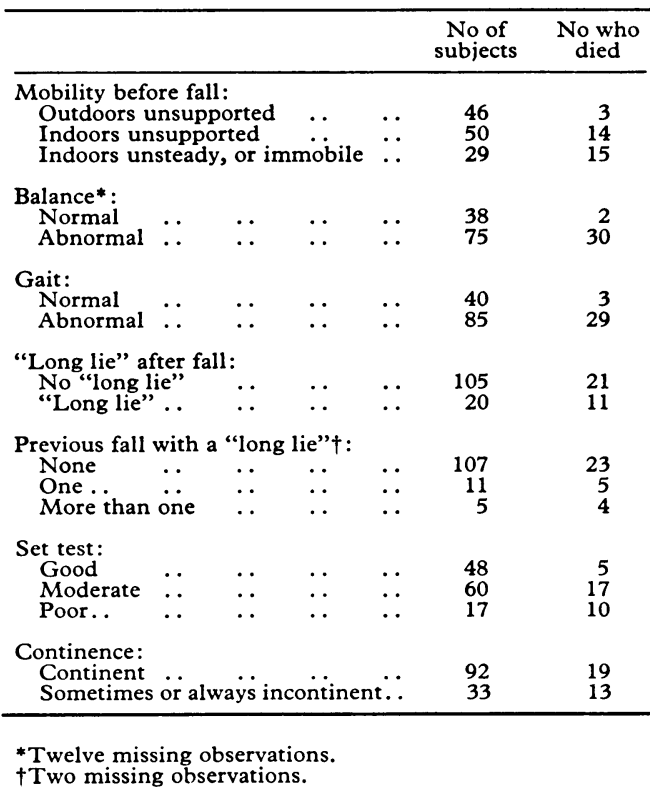

Social circumstances-Half of the fallers lived alone and one-fifth lived with an aged spouse only. There was no significant difference between fallers and controls in their living arrangements. Fallers made more use than did controls of home helps and community nurses; and more fallers lived in residential homes. One half of the fallers and a similar proportion of the controls lived in houses that were equipped with a telephone, but only 10 fallers, nine of them in sheltered housing, had an alarm system. No faller used the telephone after falling, but one received an incoming call and was able to indicate her plight. Of the nine fallers with a call system, two used it successfully, one attempted unsuccessfully to use it, and the other six made no attempt to use it.

\section{Discussion}

Falls in old people at home are not usually due to external hazards but reflect instability associated with impaired general health. No doubt many different physiological mechanisms play a part; and retrospective inquiries some days after the occurrence of the fall cannot be expected to identify these. Little evidence was found, however, to support the statements frequently made that falls in old age are often caused by vertebrobasilar ischaemia, cervical spondylosis, and the like. It seems much more common for falls to result from errors in environmental perception, slowing of responses, and weakness of support; but a great deal more needs to be known about the circumstances of the falls before this assertion can be made with confidence. Those at risk of falling are people aged 75 and over who are housebound and have an abnormal gait, tending to clutch on to furniture, to grip a walking frame, to express fear of falling while on their feet, and to walk with short irregular steps. The very grave prognosis in those who fall may reflect the fact that fallers are generally ill. Possibly the experience of falling shortens life, but our evidence does not support that belief, except in those cases when the fall led to a prolonged period lying on the ground.

Any policy for the prevention of falls should put emphasis on the physical state of the faller. Hypnotics, sedatives, and tranquillisers should not be prescribed for the very frail. Antihypertensive and antidepressant medication and alcohol present a further small potential risk.

Many of the very old who were most at risk of falling lived alone or had only limited support. Telephones and alarm devices were unsuccessful in drawing attention to their plight. Those at risk may be readily identified. They probably constitute not more than one per cent of any practice list and are in touch with the family doctor. Organising a preventive visiting service for them should not be beyond the resources of the average general practice. The visit should include a review of medication, a check of blood pressure, a general physical examination, a search for environmental hazards, and a review of the arrangements for surveillance, especially in the event of a further fall. This need incur no special costs. The more elaborate system practised in the Borough of Stockport ${ }^{6}$ and elsewhere in which radio-controlled home helps are summoned to the homes of old people who have fallen is an imaginative technical advance; but there is room also for less costly and less elaborate schemes.

We thank the patients and controls who willingly collaborated in the study; the participating general practitioners (listed below), their receptionists, and community nurses; the home-help service and police service in each practice area; the University of Birmingham Computer Centre; and the DHSS Small Grants Committee, who funded the study.

Participating general practitioners: A Benn, J P Blacker, $M$ Clarkson, A V Cowan, D L Crombie, R Davis, A R Dewsbury, V W M Drury, C M Green, J Morrison, A J Pearce, L A Price, R J F Pinsent, E Price, J Price, N Smith, B S Wyatt, R C Wynee.

\section{References}

1 Grimley-Evans J, Prudham D, Wandless I. A prospective study of fractured proximal femur. Public Health 1979;93:235-41.

2 Brocklehurst JC, Exton-Smith AN, Lempert Barber SN, Hunt LP Palmer MK. Fracture of the femur in old age: a two centre study of associated clinical factors and the cause of the fall. Age Ageing 1978; 7:7-15.

${ }^{3}$ Gray B. Home accidents among older people: report of a research carried out in the Birmingham area. London: Royal Society for the Prevention of Accidents, 1966.

4 Gryfe CI, Amies A, Ashley MJ. A longitudinal study of falls in an elderly population: incidence and morbidity. Age Ageing 1977;6:201-10.

${ }^{5}$ Ashley MJ, Gryfe CI, Amies A. A longitudinal study of falls in an elderly population. II. Some circumstances of falling. Age Ageing 1977; 6:211-20.

${ }^{6}$ Social Services Department. Mobile alarm system for home emergencies. Stockport: Social Services Department, 1979.

(Accepted 7 November 1980)

crves. Called also Rush Leeks, Chives, Civet, and Sweth. I confess I had not added these, had it not been for a country gentleman, who by a letter certified me, that amongst other herbs, I had left these out; they are indeed a kind of leeks, hot and dry in the fourth degree as they are, and so under the dominion of Mars; if they be eaten raw, (I do not mean raw, opposite to roasted or boiled, but raw, opposite to chymical preparation) they send up very hurtful vapours to the brain, causing troublesome sleep, and spoiling the eye-sight, yet of them prepared by the art of the alchymist, may be made an excellent remedy for the stoppage of the urine. (Nicholas Culpeper (1616-54) The Complete Herbal, 1850.) 